\title{
REPRESENTAÇÕES MENTAIS UTILIZADAS POR ALUNOS DO ENSINO FUNDAMENTAL NO ESTUDO DO SISTEMA RESPIRATÓRIO HUMANO
}

\author{
MENTAL REPRESENTATIONS USED BY ELEMENTARY SCHOOL STUDENTS \\ ON THE STUDY OF THE HUMAN RESPIRATORY SYSTEM
}

DOI: http://dx.doi.org/10.23926/RPD.2526-2149.2018.v3.n2.p477-491.id199

\section{Tiago Rodrigues da Silva \\ Graduado em Licenciatura em Ciências Biológicas (IFMA). \\ Professor de Ciências da Rede Municipal de Timon- MA.}

\section{Bruna Rodrigues da Silva Graduada em Bacharelado em Ciências Biológicas (UFPI).}

Resumo: $O$ artigo tem como objetivo identificar e analisar os tipos de representações mentais, com base na Teoria dos Modelos Mentais de Johnson-Laird, utilizadas por alunos do ensino fundamental para explicar o sistema respiratório humano. A abordagem foi quali-quantitativa, sendo caracterizada por um estudo descritivo e exploratório. As representações estabelecidas pelos alunos foram categorizadas em proposicionais, imagem e modelo mental. Participaram da pesquisa 31 alunos no $8^{\circ}$ ano do ensino fundamental de uma escola pública de Timon/MA. As análises ocorrem através das representações pictóricas estabelecidas pelos alunos antes e após as aulas teóricas e expositivas sobre o sistema corpóreo estudado. Com os conhecimentos prévios, foi verificado que os alunos elaboraram suas representações mentais, nas categorias proposicionais $(34 \%)$, imagem mental (54\%) e modelo mental (12\%). Após a organização dos conhecimentos, os alunos demonstraram maior capacidade em estabelecer modelos mentais (69\%) e imagem mental (23\%), ocorrendo uma diminuição de proposicionais (8\%). Com os resultados obtidos foi identificado que, com as aulas teóricas e expositivas os alunos reconstruíram suas representações mentais com a aquisição de conhecimentos científicos. Torna-se possível concluir que ocorreu uma evolução na compreensão dos alunos e de suas representações mentais sobre o sistema respiratório.

Palavras-chave: Representações. Modelos. Aprendizagem.

\begin{abstract}
The article aims to identify and analyze the types of mental representations, based on the mental models theory by Johnson-Laird, used by elementary school students to explain the human respiratory system. The study had a qualitative and quantitative approach, which was characterized by a descriptive and exploratory research. The representations established by the students were categorized as propositional, image, and mental model. Thirty-one students from the 8th grade of a public school in Timon/MA participated in the study. The analyses were carried out through the pictorial representations established by the students before and after the theoretical and expositive lectures on the human body system. The previous knowledge allowed verifying that the students were able to elaborate their mental representations, in the propositional categories (34\%), mental image (54\%), and mental model (12\%). After the knowledge organization, the students showed a greater capacity to establish mental models (69\%) and mental image $(23 \%)$, with a decrease of propositional ones $(8 \%)$. The results indicated that, with the theoretical and expositive lectures, the students reconstructed their mental representations and acquired scientific knowledge. Therefore, it was observed in this study an evolution in the students' understanding and their mental representations on the respiratory system.
\end{abstract}

Keywords: Representations. Models. Learning. 


\section{INTRODUÇÃO}

As representações mentais retratam um processo de interpretações do mundo interno para o externo, através das funções e conhecimentos presentes nas estruturas cognitivas do sujeito. Esta capacidade é resultado das interações que ocorrem entre o indivíduo com o seu meio ambiente. Desse modo, os estudos da Psicologia Cognitiva atrelada a Didática das Ciências afirmam que os alunos costumam aprender a partir da construção de suas representações sobre os conteúdos em suas mentes (MOREIRA, 1996).

No processo de elaboração das representações mentais, os conhecimentos prévios ganham um importante destaque, de tal forma que a sua interação com a aquisição de novos conceitos e significados permitem a reconstrução das representações, a partir de uma aprendizagem. Nesse sentido, o sujeito pode aprender com base nos conhecimentos prévios relevantes que traz consigo, definidos como subsunçores. Tais conhecimentos já existentes nas estruturas cognitivas do indivíduo recebem novos significados e interpretações, que por sua vez, se modificam e dão outras significações àqueles já presentes nos conhecimentos prévios (MOREIRA, MASINI, 2009).

Desta forma, os estudos de representações mentais proporcionam compreensões dos processos de construção dos conceitos e seus significados, a partir das mudanças dessas representações (MOREIRA; LAGRECA; PALMEIRO, 2002). Em função disso, as análises são envolvidas, principalmente na teoria dos modelos mentais por Johnson-Laird (1987), uma vez que apresenta relações diretas com os processos cognitivos e o ensino e aprendizagem em Ciências (MOREIRA, 1996; KRAPAS et al., 1997; BORGES, 1999; MOREIRA; LAGRECA; PALMEIRO, 2002; ARRUDA, 2003; QUINTO; FERRACIOLI, 2008; DUSSO et al., 2013; SOUZA, 2013).

Referente ao ensino do corpo humano nas perspectivas da Teoria dos Modelos Mentais, foram encontradas apenas as contribuições dos estudos de Krause (2012) e Dusso et al. (2013). Desse modo, as atividades de conceitualização de sistemas corpóreos humanos por meio de representações mentais ainda é um campo pouco explorado, pois é um objeto de estudo especifico da Biologia (TALAMONI; BERTOLLI FILHO, 2009).

Nessa perspectiva, optou-se por desenvolver a pesquisa, para contribuir no entendimento dos processos de negociação e suas relações entre os modelos construídos pelos alunos durante a aprendizagem com os modelos da ciência (TAUCEDA; DEL PINO, 2010). Trata-se de uma pesquisa que busca responder a seguinte questão: Quais são as representações 
mentais sobre o sistema respiratório humano, antes e após as aulas de Ciências, de alunos no oitavo ano do ensino fundamental de uma escola pública em Timon, Maranhão?

O presente artigo tem como objetivo identificar e analisar os tipos de representações mentais, a partir da perspectiva de Johnson-Laird (1987), que alunos de uma turma de ensino fundamental $\left(8^{\circ}\right.$ ano) possuem sobre o sistema respiratório humano. Desta forma, o trabalho busca discutir a influência das representações mentais como procedimento metodológico de ensino e de aprendizagem significativa em Ciências.

\section{REFERENCIAL TEÓRICO}

Os processos cognitivos humanos operacionalizam, de modo geral, conforme a teoria dos modelos mentais de Johnson-Laird (1987) ao postular que a mente humana opera através de três tipos de representações mentais interrelacionadas: proposicionais, modelos mentais e imagens (MOREIRA, 1996; MOREIRA; LAGRECA; PALMEIRO, 2002; PALMEIRO; MOREIRA, 2002).

Os modelos mentais são representações análogas de estruturas das coisas do mundo, de tal modo como são percebidos e vistos. Essa analogia pode variar de unidades com algum ponto mínimo análogo até um conjunto de sequência que forma um modelo mental com mais analogia ao que se interpreta do mundo exterior (JOHNSON-LAIRD, 1987). Por isso, para Moreira, Lagreca e Palmeiro (2002) os modelos mentais são expressos de forma semelhante às estruturas e aspectos que correspondem a uma situação que o representa, desempenhando um papel funcional, análogo e direto.

Conforme Johnson-Laird (1987) as representações do tipo proposicionais são definidas por serem proposições verbais que podem ou não estar em concordância com o estado das coisas do mundo, podendo se referir sobre situações hipotéticas ou imaginárias de como o sujeito concebe suas representações internas. Nesse sentido, as proposicionais são as representações mentais em forma de palavras, por isso apresentam comumente suas expressões de forma verbal (MOREIRA; LAGRECA; PALMEIRO, 2002).

As imagens mentais são as representações visuais específicas e são perspectivas de um modelo mental (JOHNSON-LAIRD, 1987). Outra definição para imagens mentais é a de Moreira, Lagreca e Palmeiro (2002) ao afirmarem que elas são resultados dos processos imaginários que o sujeito possui, conforme seu ponto de vista particular.

Nesse sentido, a função e significados de cada representação é o ponto central para suas diferenciações sendo as imagens e modelos mentais consideradas representações de alto nível 
para o entendimento da cognição humana (JOHNSON-LAIRD, 1987). Tanto os modelos mentais como as representações na forma de imagem são suscetíveis a mudanças, ou seja, instáveis nas estruturas cognitivas do indivíduo, uma vez que podem sofrer reconstruções na medida em que o sujeito adquire novas percepções e interpretações do mundo externo (MOREIRA, 1996; MOREIRA; LAGRECA, 1998; MOREIRA; LAGRECA; PALMEIRO, 2002).

A teoria dos modelos mentais contribui de forma significativa para uma reflexão sobre a cognição humana (KRAPAS et al., 1997; QUINTO; FERRACIOLI, 2008). Por isso, os conceitos das representações mentais, sobretudo as do tipo modelo passaram a não ser mais unitários nos últimos anos, a partir do momento que começaram a ser utilizados em várias áreas do conhecimento (BORGES, 1999). O que parece fundamental no campo da educação em ciência, é que os modelos mentais são

[...] uma forma de representação analógica do conhecimento: existe uma correspondência direta entre entidades e relações presentes na estrutura dessa representação e as entidades e relações que se busca representar. É composto de elementos ("tokens") e relações que representam um estado de coisas específico, estruturados de uma maneira adequada ao processo sobre o qual deverão operar [...] Estados de coisas muitas vezes são descritos por conceitos. O modelo mental de um conceito deve ser capaz de representar tanto o essencial como a sua amplitude (MOREIRA, 1996, p. 196).

Os modelos mentais, desta forma, estão relacionados diretamente com a capacidade de compreender determinados conteúdos pelo sujeito (SOUZA, 2013), configurando-se como um modelo que existe na mente do indivíduo, resultado de sua imaginação e internalização de modelos simplificados da realidade e do campo científico (BORGES, 1999), ou seja, é essencial que ele possua representações dos conceitos com suas propriedades ou descrições e símbolos (MOREIRA, 1996).

Neste ponto, os modelos mentais postulados na teoria de Johnson-Laird (1987) possuem relações intrínsecas com os modelos conceituais ou científicos, mas ambos apresentam definições e conceitos divergentes (MOREIRA, 1996; MOREIRA; LAGRECA; PALMEIRO, 2002). Tais diferenças para Krapas et al. (1997) ocorrem devido o modelo conceitual ser

[...] formalizado regulamente, compartilhado por grupos sociais com o propósito de compreender/explicar ideias, objetos, eventos, processos ou sistemas. Exemplos relevantes para a educação em ciências são os modelos científicos contemporâneos e do passado. Já o modelo mental é um modelo pessoal, construído pelo indivíduo e que pode se expressar através da ação, da fala, da escrita, do desenho (KRAPAS, 1997, p. 192).

Os modelos científicos utilizados pelos professores têm a finalidade de facilitar a compreensão dos sistemas e fenômenos químicos, físicos e biológicos, formulando assim 
modelos mentais nos alunos (MOREIRA; LAGRECA; PALMEIRO, 2002). Porém, para Souza (2013) quando os professores não compreendem que estão promovendo a elaboração de modelos nos estudantes (ou porque desconhecem os processos de formação ou pela ausência de conhecimento de suas definições) ocasionam representações mentais nos alunos que são incoerentes quando comparadas com os modelos conceituais.

Por isso, é importante que na construção de representações mentais seja proporcionado aos alunos uma aprendizagem significativa. Essa ligação evidencia que a teoria dos modelos mentais de Johnson-Laird (1987) apresenta relações diretas com as ideias construtivista de aprendizagem (RAMALHO, 2009; TAUCEDA; DEL PINO, 2010; TAUCEDA; NUNES; DEL PINO, 2011; KRAUSE, 2012; ERROBIDART et al., 2013; SOUZA, 2013).

\section{Metodologia}

O estudo foi realizado nos meses de setembro e outubro do ano de 2017, em uma escola de Ensino Fundamental (Unidade Escolar Luiz Miguel Budaruiche) da rede municipal de educação da cidade de Timon, Maranhão. A turma era de $8^{\circ}$ ano (31 alunos com uma média de faixa etária entre 13 e 14 anos).

A pesquisa ocorreu durante a aula semanal da disciplina de Ciências e em três etapas. A primeira denominada de pré-ensino foi uma atividade instrutiva e individual aos alunos, sem o auxílio do livro didático. O uso da tarefa instrucional ocorreu por ter sido uma das técnicas para análises qualitativas mais utilizadas para identificar os tipos de representações mentais pelos alunos (KRAUSE, 2012; ARRUDA, 2013).

O objetivo no pré-ensino era que os alunos elaborassem, de acordo com suas percepções, uma representação gráfica (pictórica) do sistema respiratório humano no desenho de uma silhueta já estabelecido, conforme os referencias didáticos para nível fundamental proposto pelos autores Lederman e D'Olival (2015). A atividade foi realizada na primeira aula e serviu como um diagnóstico prévio dos alunos sobre o referido sistema corpóreo. Sequencialmente, na segunda etapa foram executadas quatro aulas de 90 minutos cada uma, com o objetivo de desenvolver e ilustrar, por meio do livro didático o modelo científico da fisiologia e órgãos que compõem o sistema supracitado.

As aulas teóricas foram ministradas sempre com o foco em manter o máximo de clareza possível, utilizando uma linguagem com os termos científicos apropriados aliados com uma adequação ao nível de ensino dos alunos. 
A terceira etapa, denominada de pós-ensino foi aplicada 35 dias após a primeira e desenvolveu-se igualmente a atividade instrutiva. Em ambas, o objetivo dos discentes era atender a seguinte questão: Desenhe os componentes do sistema respiratório humano indicando o caminho que o gás oxigênio percorre no organismo até chegar aos pulmões.

Os 62 documentos (desenhos) se referem as interpretações, explicações e representações dos alunos sobre o sistema respiratório humano, sua estrutura e fisiologia nas fases do préensino e pós-ensino, cada qual com 31 desenhos. A partir disso foram aplicadas as metodologias quali-quantitativas, especificadamente, promovendo a descrição, classificação e interpretação das representações mentais dos alunos para estabelecer as suas possíveis relações entre as etapas. Desse modo, a pesquisa é caracterizada por apresentar uma abordagem descritiva e exploratória (LÜDKE; ANDRÉ, 2013; PRODANOV; FREITAS, 2013).

A identificação das representações mentais utilizados pelos alunos baseia-se na análise das características atribuídas aos conceitos relativos ao estudo do conteúdo, discutidas em sala de aula (RAMALHO, 2009; TAUCEDA; DEL PINO, 2010). Desse modo, foram categorizadas de acordo com a Teoria dos Modelos Mentais de Johnson-Laird (1987): Proposicionais (P), Imagem Mental (IM) e Modelo Mental (MM).

As estruturas representadas pelos alunos necessariamente não possuem relações claras com as esperadas para o corpo humano. Ao adotar o modelo científico do sistema corpóreo, o agrupamento das semelhanças anatômicas e fisiológicas deve ocorrer por etapas (KRAUSE, 2012). Assim, os desenhos foram divididos seguindo as correlações entre os seguintes componentes do sistema respiratório humano: a) cavidades nasais; b) faringe, laringe e traqueia; c) brônquios, pulmões e bronquíolos e d) diafragma.

\section{ReSultados E DiscuSSÕES}

$\mathrm{Na}$ etapa do pré-ensino os alunos, de modo geral, demonstraram não possuir dificuldades em sistematizar uma representação mental do sistema corpóreo estudado, bem com em aplicar conhecimentos prévios necessários para a sua esquematização. Com essas representações externas (os desenhos) os alunos estabelecem as semelhanças entre o que pensam e o que representam (RAMALHO, 2009).

Ao total foram quantificadas 124 representações mentais, nas categorias proposicionais $(\mathrm{P}=34 \%)$, imagem mental ( $\mathrm{IM}=54 \%)$ e modelo mental $(\mathrm{MM}=12 \%)$. Os resultados obtidos na atividade instrucional no pré-ensino foram sintetizados na Tabela 01. 
Tabela 01 - Tipos de representações mentais no pré-ensino

\begin{tabular}{cccc}
\hline \multirow{2}{*}{$\begin{array}{c}\text { mponentes do sistema respiratório } \\
\text { humano }\end{array}$} & \multicolumn{3}{c}{ Representações mentais } \\
\cline { 2 - 4 } & Proposicionais & $\begin{array}{c}\text { Imagem } \\
\text { Mental }\end{array}$ & $\begin{array}{c}\text { Modelo } \\
\text { Mental }\end{array}$ \\
\hline $\begin{array}{c}\text { Cavidades nasais } \\
\text { Faringe, laringe e traqueia }\end{array}$ & 17 & 12 & 02 \\
Brônquios, pulmões e bronquíolos & - & 26 & 05 \\
Diafragma & 13 & 12 & 01 \\
\hline Total & 12 & 17 & 07 \\
\hline
\end{tabular}

Fonte: Dados da pesquisa, 2017.

A ausência da interação com os conhecimentos apresentados no ensino formal justifica o fato das representações proporcionais, uma vez que ocorre a dificuldade de elaborar um modelo relacionado ao conhecimento do sistema respiratório. Percebe-se que essas representações são um produto da imaginação ou percepções a partir do senso comum dos alunos (ERROBIDART et al., 2013). Nesse caso, os discentes concebem os componentes do sistema corpóreo desarticulado com modelo cientificamente aceito.

Ao trabalhar bastante com imagens os alunos constroem sua representação mental mais imagístico do que de proposições (MOREIRA; LAGRECA, 1998). Por isso, nessa categoria estão agrupadas as interpretações dos estudantes que apresentam semelhanças com os modelos científicos do sistema respiratório humano, apesar da ocorrência da falta dos conceitos e desproporção nos tamanhos dos órgãos desenhados. De fato, isso é porque as imagens mentais formam um início de modelos explicativos para o problema proposto e são vistas de modelos mentais (MOREIRA, 1996; LAGRECA; MOREIRA, 1999; MOREIRA; LAGRECA; PALMEIRO, 2002).

A imagem mental das vias respiratórias (faringe, laringe, traqueia e brônquios) denota que os alunos possuem, em geral, uma capacidade de conhecer dentro do organismo o percurso do gás oxigênio até os pulmões, bem como da existência do diafragma (músculo localizado abaixo dos pulmões que separa a cavidade torácica da abdominal e desempenha papel fundamental para a entrada e saída de ar dos pulmões). Diante disso, Krause (2012) afirma que a imagem mental pode ser entendida como uma forma de representar visualmente uma informação espacial com auxílio da memória, com isso o sujeito pode estar ilustrando algo já visto (PALMEIRO; MOREIRA, 2003).

Os alunos que elaboraram desenhos que sugerem posições anatômicas e fisiologia dos componentes do sistema respiratório humano são os exemplos da utilização de uma representação mental do tipo modelo, considerando suas proximidades com o científico. Por 
esses motivos, os estudantes que apresentam essas representações possuem a capacidade de estabelecer ligações com os conceitos quando abordados pelo professor (LAGRECA; MOREIRA, 1999). Para Errobidart et al. (2013), isso é um indicativo que os alunos já tiveram contanto com o modelo conceitual e com possíveis representações presentes no livro didático.

Na Figura 01 é observado um exemplo de um dos alunos que utiliza duas representações mentais. A primeira proposicional (cavidades nasais), e a segunda uma imagem mental das vias respiratórias, pulmões e diafragma. Moreira e Lagreca (1998) classificam representações que usam o conjunto de proposicionais e imagens mentais de modelos híbridos e que ao final não constroem modelos biológicos, uma vez que ocorre a ausência das articulações dos conceitos e símbolos.

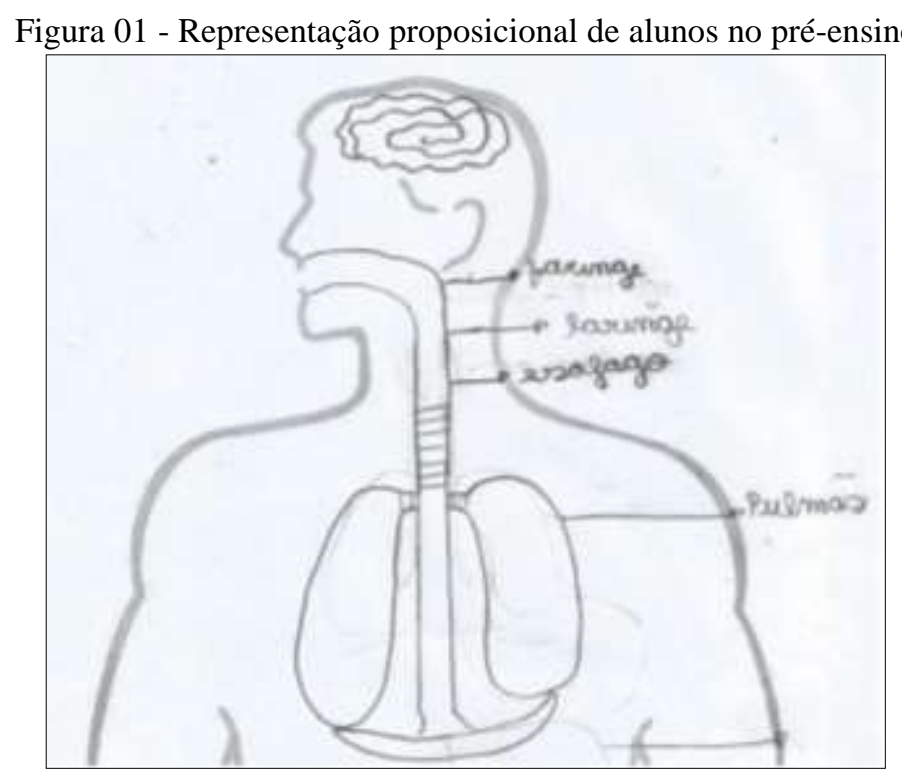

Fonte: Dados da pesquisa, 2017.

Percebe-se que nas cavidades nasais, o desenho sugere uma representação mental que a principal entrada do gás oxigênio no organismo humano seja a boca, o que evidencia uma representação desarticulada com o problema proposto e modelo científico. Nesse caso, os alunos não associam que as cavidades nasais são as responsáveis pela entrada do gás oxigênio. Logo, não conseguiram articular o fenômeno ligado a si próprio, transferindo as situações similares ou do cotidiano (MOREIRA; LAGRECA, 1998). Para Tauceda e Del Pino (2010), esses estudantes ainda não são capazes de interpretar as proposições, conforme um modelo conceitual.

A imagem mental no exemplo da Figura 01 indica uma sequência lógica e aceita das vias respiratórias após as cavidades nasais até os pulmões. No entanto, a sua continuidade ao diafragma representa uma incoerência com os componentes do sistema respiratório. As suas 
proposições não estão relacionadas com a imagem, uma vez que ocorre a ausência da nomenclatura na traqueia e brônquios (indicados pelos traços que representam as suas características estruturais, semicírculos de cartilagem) e diafragma.

Nesse sentido, os alunos ao utilizarem a predominância de imagens e símbolos possuem uma concepção puramente imagística, ocorrendo uma ausência de explicações do modelo, por sua vez não construindo necessariamente o modelo biológico aceito, mas que responde parcialmente ao problema proposto (TAUCEDA; DEL PINO, 2010).

Por outro lado, na Figura 02 o aluno apresenta, de modo geral, um modelo cientificamente aceito quando se trata da entrada do gás oxigênio no corpo e do diafragma. Entretanto, concebe uma imagem mental das vias respiratórias e de estruturas localizadas no interior dos pulmões, como os bronquíolos. Desse modo, apresenta certa consistência anatômica e fisiológica do sistema corpóreo.

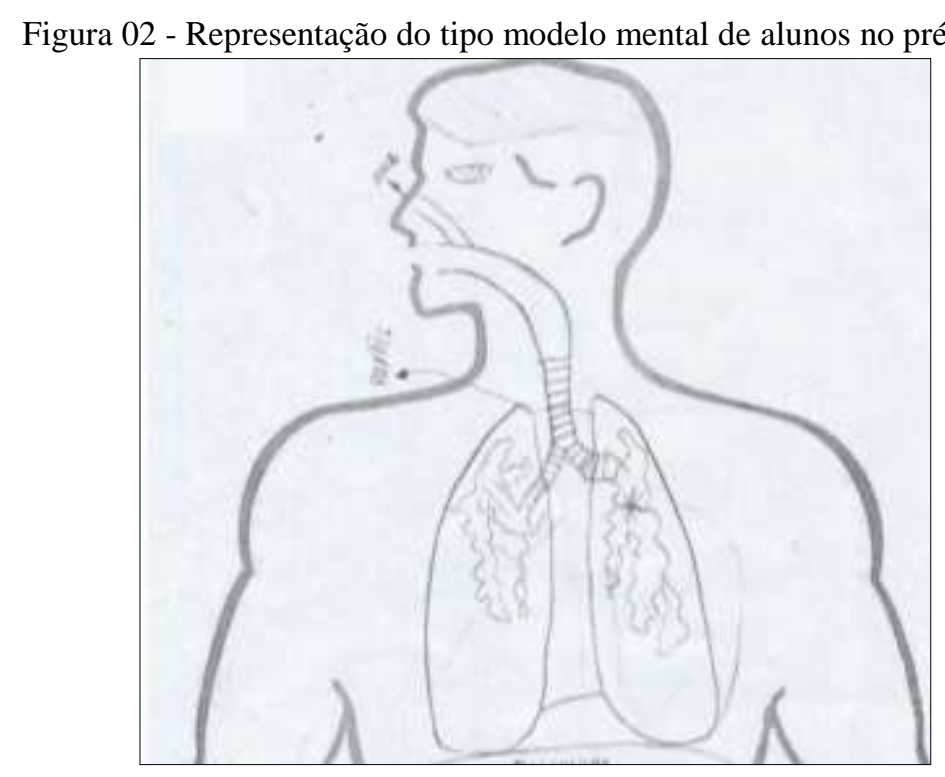

Fonte: Dados da pesquisa, 2017

As representações, dessa forma, denotam a existência de uma representação bruta do sistema respiratório, apresentando segundo Tauceda e Del Pino (2010), certa similaridade com o modelo científico. Verifica-se, então, que o estudo do sistema respiratório humano apresenta articulações de conceitos e ideais com o cotidiano dos alunos. Fica evidenciado que as representações mentais no pré-ensino foram os conhecimentos prévios existentes em suas estruturas cognitivas.

Em geral, o objetivo durante os processos de ensino e aprendizagem na sala de aula era que os conhecimentos prévios dos alunos adquirissem novos significados antes da aplicação da atividade no pós-ensino. Desta forma, permite uma reformulação das representações mentais e 
possíveis construções de modelos mentais mais elaborados e próximos dos conceituais (MOREIRA, 1996). Assim, com relação aos resultados da tarefa instrucional na etapa do pósensino (Tabela 02), observou-se que das 124 representações foram quantificadas em maior número as do tipo modelos mentais ( $\mathrm{MM}=69 \%)$ e imagem mental ( $\mathrm{IM}=23 \%)$, ocorrendo uma diminuição de proposicionais $(\mathrm{P}=8 \%)$.

Tabela 2 - Tipos de representações mentais no pós-ensino

\begin{tabular}{cccc}
\hline \multirow{2}{*}{$\begin{array}{c}\text { Componentes do sistema } \\
\text { respiratório humano }\end{array}$} & Proposicionais & $\begin{array}{c}\text { Imagem } \\
\text { Mental }\end{array}$ & $\begin{array}{c}\text { Modelo } \\
\text { Mental }\end{array}$ \\
\cline { 2 - 4 } & 03 & 05 & 31 \\
Cavidades nasais & 05 & 10 & 13 \\
Faringe, laringe e traqueia & 02 & 07 & 19 \\
Brônquios, pulmões e bronquíolos & - & 09 & 23 \\
Diafragma & $\mathbf{1 0}$ & $\mathbf{2 8}$ & $\mathbf{8 6}$ \\
\hline Total & Fonte: Dados da pesquisa, 2017 &
\end{tabular}

Essa redução traduz que alguns alunos ainda não superaram a ideia de trabalhar com representações isoladas, memorizadas e sem significados, ou seja, compreenderam os conceitos isoladamente sem ocorrer inter-relação com a construção de modelos (LAGRECA; MOREIRA, 1999). Porém, essa queda percentual de $26 \%$ reflete que os estudantes também passaram a interpretar as proposições e a construir imagens e modelos mentais similares aos científicos (MOREIRA; LAGRECA; PALMEIRO, 2002).

A diminuição percentual de $31 \%$ na quantidade de representações do tipo imagem mental nas etapas do pré para o pós-ensino indica que os alunos atribuíram novos significados a suas percepções e interpretações do sistema respiratório humano, o que constata uma evolução em seus conhecimentos prévios. Moreira e Masini (2009) afirmam que os subsunçores possuem a capacidade de dar novos significados a outros conhecimentos, promovendo a reconstrução de suas concepções e modelos. De fato, as imagens mentais são uma forma dos sujeitos operaram mentalmente sua aprendizagem (PALMERO; ACOSTA; MOREIRA, 2001).

Situando-se sobre o estudo do corpo humano na educação básica, Talamoni e Bertolli Filho (2009) abordam que a formação de conceitos sobre os sistemas corpóreos quando aplicado de forma ampla favorece a apropriação do próprio corpo pelos alunos, contribuindo para permitir relações entre suas vivências e o conhecimento científico, o que resulta em representações que exercem uma aprendizagem.

Com isso, foi possível constatar que o aumento do número de modelos mentais de 12 para 69 durante o pré e pós-ensino, ou seja, um acréscimo percentual de 57\% entre as etapas 
representa que os alunos apresentaram uma evolução na capacidade de compreender o sistema respiratório humano durante as descrições e interações na prática docente.

Percebe-se que durante as aulas teóricas os conhecimentos prévios sobre o sistema corpóreo estudado foram elaborados e reformulados pelos alunos, tornando-se diferenciados e com capacidade dos mesmos em construir modelos mentais semelhantes aos conceituais. Neste direcionamento, os estudantes conseguiram reconstruir seus modelos que usavam antes, o que significa que aprenderam a ver o sistema respiratório humano com outra perspectiva ao incluir novos elementos que estavam ausentes nas representações antigas e em suas estruturas cognitivas.

Os alunos corroboraram o conhecimento prévio ao promover maior estabilidade em sua cognição e clareza sobre os conteúdos na medida em que realizam novas representações (MOREIRA; MASINI, 2009). Assim, o atual modelo do aluno depende do nível das possibilidades de integrar os conhecimentos prévios com a introdução de seus novos significados, de modo que isso pode ser feito quando os alunos recebem auxílios na construção de modelos mentais semelhantes aos científicos que irão estudar (BORGES, 1999).

Os desenhos dos alunos que correspondem a representações na forma de modelos mentais desempenham um papel de representação analógica as estruturas que compõem o sistema respiratório humano, de forma que se torna reflexo de aspectos relevantes do modelo científico, correspondendo a mundo real e imaginário (MOREIRA; LAGRECA; PALMEIRO, 2002).

Atribui-se isso como um resultado que pode ser considerado como um indicador que os estudantes compreenderam parte dos conteúdos. Desta maneira, se observa na Figura 3 (A e B) que os desenhos pictóricos dos alunos demonstram maiores proposições e explicações do caminho que o gás oxigênio percorre para chegar aos pulmões.

Figura 03 - Exemplos de representação pictórica de modelos mentais dos alunos no pós-ensino 


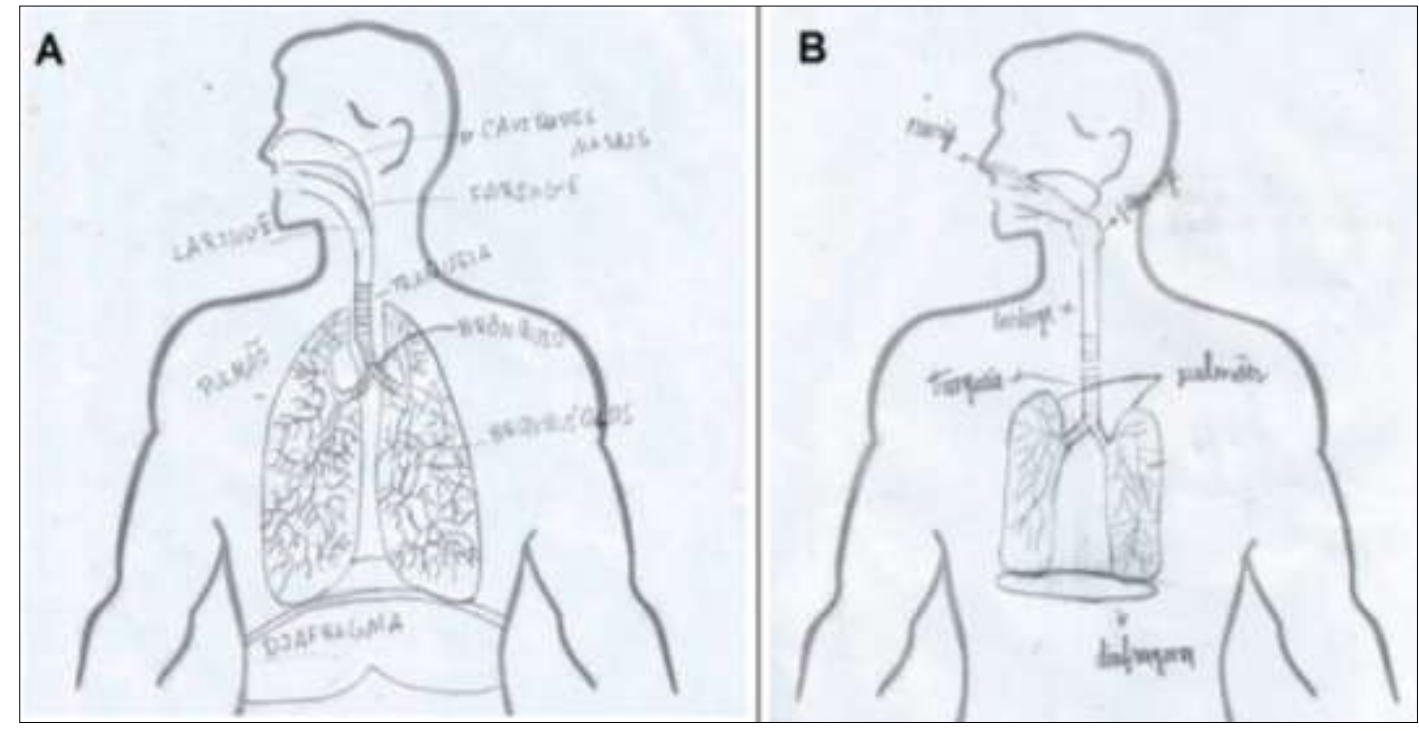

Fonte: Dados da pesquisa, 2017

A representação na Figura 03 (A) indica uma sequência dos componentes do sistema das cavidades nasais até os pulmões com os bronquíolos, bem como do diafragma, expressando uma concordância com o modelo conceitual. Por outro lado, no exemplo B na Figura 03 o modelo não está totalmente completo, pois faltam as proposições dos brônquios, apesar da ilustração sugerir uma imagem mental a partir dos símbolos (traços sublinhados após a traqueia) desse componente.

Por isso, torna-se possível afirmar que as representações na Figura 3 (A e B) mostram similaridades com o modelo cientifico, respondendo o problema proposto na atividade instrucional. Para Dusso e colaboradores (2013) os desenhos pictóricos dos estudantes podem ser definidos como um modelo representacional, uma vez que é caracterizado como sendo uma representação de um sistema corpóreo humano.

Tauceda, Nunes e Del Pino (2011) em seus estudos de representações mentais e o livro didático, afirmam que os alunos podem ter dificuldades em formar modelos mentais que possam ser explicativos e funcionais devido ao uso excessivo de suas imagens, e os estudantes que produzem modelos sem utilização do livro didático possuem uma tendência em desenvolvê-los com uma aprendizagem significativa.

Na Figura 3 (A) há indícios que a representação do aluno pode ser uma cópia, uma memorização do modelo conceitual do sistema corpóreo estudado presente no livro didático abordado durante as aulas, uma vez que apresenta maiores semelhanças com as suas figuras. Desta forma, o aluno não procura construir sua própria representação mental. Neste caso, as informações presentes no desenho podem ser somente as lembranças para resolver o problema, indicando uma possível falta de reflexão resultante das discussões conceituais e observações 
das imagens do livro didático, lembrando uma repetição e uma aprendizagem mecânica (TAUCEDA; DEL PINO, 2010).

Por sua vez, na Figura 3 (B) a representação do aluno transcreve um modelo mais próprio, individual do sistema respiratório humano. O que compreende a ocorrência de uma interação dos novos conceitos com os prévios, redefinindo suas representações nas etapas do pré-ensino e pós-ensino. Nesse debate, Tauceda, Nunes e Del Pino (2011) dizem que os alunos conseguem relacionar e interpretar modelos a partir de seus subsunçores com os conhecimentos que foram adquiridos, construindo, na maioria das vezes, modelos mais explicativos e funcionais com uma aprendizagem significativa.

As novas proposições e significados que foram atribuídos nas representações mentais no pós-ensino pelos alunos traduzem a sua capacidade de compreender modelos científicos, entendendo situações e contextos diferentes trabalhados em sala de aula. Esses resultados para Moreira e Lagreca (1998) indicam que os estudantes podem formar modelos mentais mais elaborados com funções explicativas a partir da aquisição de conhecimentos científicos.

\section{CONSIDERAÇÕES FINAIS}

Diante dos resultados encontrados, percebe-se que o uso dos desenhos pictóricos para a representação mental dos alunos ocorreu de forma satisfatória. As reflexões em torno das representações mentais dos alunos demonstram um caráter plural, ou seja, são utilizados, na maioria das vezes, mais de um tipo de representação para responder o problema proposto.

Vale destacar que as representações na etapa do pré-ensino apresentaram certa diferença ao modelo conceitual do sistema respiratório humano quando comparada com os resultados obtidos no pós-ensino. Por consequência, constatou-se uma evolução nas representações mentais dos alunos. Torna-se, possível concluir que após as aulas teóricas se obteve melhores concepções e interpretações dos conteúdos por parte dos alunos. Logo, um maior número de representações do tipo imagem e modelo mental.

Tais resultados reafirmam que o ensino do corpo humano deve ocorrer de forma ampla e contextualizada para que os alunos possam se inserir como parte dos conteúdos e se identificar com a anatomia e processos fisiológicos dos sistemas corpóreos. A partir disso, observaram-se as evoluções dos conhecimentos prévios dos alunos na medida em que foram atribuíram novos significados, resultando em uma ligação cognitiva com os conceitos científicos discutidos, o que elucida as relações diretas que as representações mentais apresentam com as abordagens construtivas no ensino e aprendizagem em Ciências. 


\section{REFERÊNCIAS}

ARRUDA, D. M. Modelos mentais. Instituto Nacional de Tecnologia. Brasília, 2003.

BORGES, A. T. Como evoluem os modelos mentais. Revista Ensaio, Belo Horizonte. v. 1, n.1, p.66-92, jan./jun., 1999.

DUSSO, L.; et al. Modelização: uma possibilidade didática no ensino de Biologia. Revista Ensaio, Belo Horizonte. v.15, n. 2, maio/ago., p. 29-44, 2013.

ERROBIDART, N. C. G.; et al. Modelos mentais e representações utilizadas por estudantes do ensino médio para explicar ondas. Revista Electrónica de Enseñanza de las Ciencias, v. 12, n. 3, p.440-457, 2013.

JOHNSON-LAIRD, P. Modelos mentais em ciência cognitiva. In: NORMAN. D. (Ed.). Perspectivas de la Ciência Cognitiva. Barcelona: Paidós, 1987.

KRAPAS, S.; ALVES, F.; CARVALHO, L. R. Modelos mentais e a lei de Gauss. Investigações em Ensino de Ciências, v. 5, p. 1, p. 7-21, 2000.

KRAPAS, S. et al. Modelos: uma análise de sentidos na literatura de pesquisa em ensino de Ciências. Investigações em Ensino de Ciências, v. 2 n. 3, p. 185-205, 1997.

KRAUSE, F. C. Modelos tridimensionais em Biologia e aprendizagem significativa na Educação de Jovens e Adultos (EJA) no Ensino Médio. 186f. 2012. Dissertação (Mestrado em Educação). Universidade de Brasília, Brasília, 2012.

LAGRECA, M. C. B.; MOREIRA, M. A. Tipos de representações mentais utilizadas por estudantes de Física Geral na área de mecânica clássica e possíveis modelos mentais nessa área. Revista Brasileira de Ensino de Física, v. 21, n. 1, p. 202-215, 1999.

LEDERMAN, L.; D'OLIVAL, F. C. Tempo de ciências 8. 2. ed, São Paulo: Editora do Brasil, 2015.

LÜDKE M.; ANDRÉ, M. E. D. A. Pesquisa em educação: abordagens qualitativas. 2. ed. São Paulo: EPU, 2013

MOREIRA, M. A. Modelos mentais. Investigações em Ensino de Ciências, v. 1, n. 3, p.193232, 1996.

MOREIRA, M. A; GRECA, I. M.; PALMERO, M. L. R. Modelos mentales y modelos conceptuales en la enseñanza y aprendizaje de las Ciencias. Revista Brasileira de Pesquisa em Educação em Ciências, Porto Alegre, v. 2, n. 3, p. 37-57, 2002.

MOREIRA, M. A; LAGRECA, M. C. B. Representações mentais dos alunos em mecânica clássica: três casos. Investigações em Ensino de Ciências, v. 3, n. 2, p. 83-106, 1998.

MOREIRA, M. A; MASINI, E. F. S. Aprendizagem significativa: a teoria da aprendizagem de David Ausubel. 2. ed. São Paulo: Centauro Editora, 2009. 
PALMERO, M. L. R.; ACOSTA, J. M.; MOREIRA, M. A. La teoría de los modelos mentales de Johnson-Laird y sus principios: una aplicación con modelos mentales de célula em estudiantes del curso de orientación universitária. Investigações em Ensino de Ciências, v. 6, n. 3, p. 243-268, 2001.

PALMERO, M. L. R.; MOREIRA, M. A. Modelos mentales vs esquemas de célula. Investigações em Ensino de Ciências, v. 7, n. 1, p. 77-103, 2002.

PRODANOV, C. C.; FREITAS, E. C. Metodologia do trabalho científico: métodos e técnicas da pesquisa e do trabalho acadêmico. 2. ed. Novo Hamburgo: Feevale, 2013.

QUINTO, T.; FERRACIOLI, L. Modelos e modelagem no contexto do ensino de Ciências no Brasil: uma revisão de literatura de 1996-2006. Revista Didática Sistêmica, v. 8, jul./dez., p. 80-100, 2008.

RAMALHO, F. A. Modelos e representações análogas de alunos da educação de jovens e adultos - EJA - no ensino de ciências. 2009. 153 f. Mestrado (Educação Tecnológica). Centro Federal de Educação Tecnológica de Minas Gerais. Belo Horizonte, 2009.

SOUZA, E. S. R. A formação de modelos mentais na sala de aula. Revista EXITUS, v. 3, n.1, jan./Jun., p. 169-184, 2013.

TALAMONI, A. C. B.; BERTOLLI FILHO, C. A formação de conceitos no ensino de Biologia e Química: corpo e vida nas representações de estudantes do ensino fundamental. In: CALDEIRA, A. M. A. (Org.) Ensino de Ciências e Matemática, II: temas sobre a formação de conceitos. São Paulo: Editora UNESP, 2009.

TAUCEDA, K. C.; DEL PINO, J. C. Modelos e outras representações mentais no estudo do DNA em alunos do ensino médio. Investigações em Ensino de Ciências, v. 15, n. 2, p. 337$354,2010$.

TAUCEDA, K. C.; NUNES, V. M.; DEL PINO, J. C. O livro didático e as representações mentais de Bioquímica e Biofísica em alunos do Ensino Médio. Experiências em Ensino de Ciências, v. 6, n. 1, p. 57-68, 2011.

Recebido em: 18 de maio de 2018. Aprovado em: 20 de agosto de 2018. 